\title{
qPCR-based environmental monitoring of Myxobolus cerebralis and phylogenetic analysis of its tubificid hosts in Alberta, Canada
}

\author{
Danielle E. Barry ${ }^{1}$, Marie Veillard ${ }^{2,3}$, Clayton T. James ${ }^{2,3}$, Leah Brummelhuis ${ }^{1}$, \\ Emmanuel A. Pila ${ }^{2}$, Alyssa Turnbull ${ }^{1}$, Arnika Oddy-van Oploo ${ }^{1}$, XinNeng Han ${ }^{1}$, \\ Patrick C. Hanington ${ }^{1, *}$
}

${ }^{1}$ Environmental Health Sciences, School of Public Health, University of Alberta, Edmonton, Alberta T6G 1C9, Canada

${ }^{2}$ Alberta Environment and Parks, Government of Alberta, Edmonton, Alberta T5K 2G6, Canada

${ }^{3}$ Present address: Fisheries and Oceans Canada, Government of Canada, Edmonton, Alberta T6X 0J4, Canada

\begin{abstract}
Myxobolus cerebralis is the causative agent of whirling disease in salmonid fishes. In 2016, this invasive parasite was detected in Alberta, Canada, for the first time, initiating a comprehensive $3 \mathrm{yr}$ monitoring program to assess where the parasite had spread within the province. As part of this program, a qPCR-based test was developed to facilitate detection of the environmental stages of $M$. cerebralis and from the oligochaete host, Tubifex tubifex. During this program, 1500 environmental samples were collected and tested over $3 \mathrm{yr}$. Fish were collected from the same watersheds over $2 \mathrm{yr}$ and tested as part of the official provincial monitoring effort. Substrate testing identified sites positive for $M$. cerebralis in 3 of 6 watersheds that had been confirmed positive by fish-based testing and 3 novel detections where the parasite had not been detected previously. Testing of individually isolated Tubifex from each sample site was used to further confirm the presence of $M$. cerebralis. DNA barcoding of the cytochrome oxidase I ( $\operatorname{cox} 1)$ gene of 567 oligochaete specimens collected from 6 different watersheds yielded 158 unique sequences belonging to 21 genera and 37 putative species. Phylogenetic analyses of sequences assigned to the genus Tubifex predicted 5 species of Tubifex arising from this assessment. Based on our results, we propose that environmental and worm samples can be a valuable complement to the gold-standard fish testing and will be especially useful for monitoring in areas where fish collection is challenging or prohibitive because of site accessibility or vulnerability of the fish populations.
\end{abstract}

KEY WORDS: Whirling disease $\cdot \mathrm{qPCR} \cdot$ Myxozoa $\cdot$ Environmental monitoring $\cdot$ Disease transmission

\section{INTRODUCTION}

Whirling disease in fish is caused by a myxosporean parasite, Myxobolus cerebralis (Hofer, 1903). This parasite has a 2-host life cycle, utilizing a salmonid fish host and an aquatic oligochaete host (Markiw \& Wolf 1983). Myxospores develop in the

${ }^{*}$ Corresponding author: pch1@ualberta.ca fish host and are released from both live and decaying fish (Nehring et al. 2002); these spores are infective to the oligochaete host when consumed. The myxospores settle into the substrate where they are ingested by the oligochaete host, Tubifex tubifex (Müller 1774). Triactinomyxon-type actinospores (TAMs) are produced by the parasite while infecting

(C) The authors 2021. Open Access under Creative Commons by Attribution Licence. Use, distribution and reproduction are unrestricted. Authors and original publication must be credited. 
T. tubifex and are released into the water column, where they infect fish by attaching to gills and skin or via ingestion (Gilbert \& Granath 2003). Originally from Europe, $M$. cerebralis is invasive in North America, having established first in Pennsylvanian hatcheries in 1958 (Hoffman et al. 1962). This parasite has been responsible for significant declines of wild fish populations and stocked trout in North America, most notably in Colorado and Montana (Nehring \& Walker 1996, Vincent 1996).

M. cerebralis was first detected in Canada in Johnson Lake in Banff National Park, Alberta, in August 2016 (Canadian Food Inspection Agency 2016). Little is known about the establishment and transmission of this parasite in Canada. Following the detection in Johnson Lake, 4 major watersheds were declared positive for $M$. cerebralis based on fish testing undertaken by the Canadian Food Inspection Agency and Alberta Environment and Parks, including the Bow River, Oldman River, Red Deer River and North Saskatchewan River watersheds (Fig. 1). Salmonid

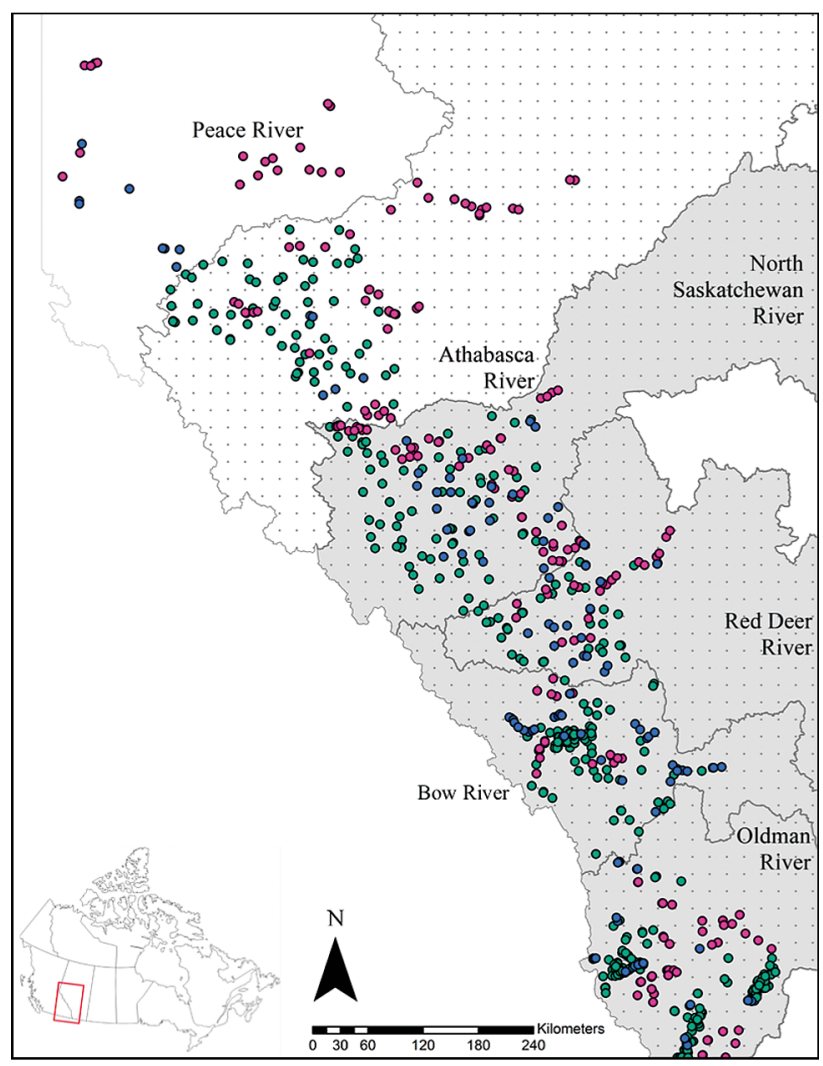

Fig. 1. Sites in Alberta, Canada, sampled in 2016 (blue), 2017 (pink) and 2018 (green), covering 6 watersheds. Watersheds declared positive for Myxobolus cerebralis by fish host testing are shaded; watersheds that have had positive worm host or substrate results are additionally stippled species in Alberta that are known to be susceptible to whirling disease include rainbow trout Oncorhynchus mykiss Walbaum, 1792, cutthroat trout O. clarkii Richardson, 1836, brook trout Salvelinus fontinalis Mitchill, 1814, brown trout Salmo trutta Linnaeus, 1758 and mountain whitefish Prosopium williamsoni Girard 1856. Of these species, westslope cutthroat trout O. clarkii lewisi Suckley 1856 and Athabasca rainbow trout O. mykiss (Rasmussen \& Taylor 2009) are listed under the Federal Species at Risk Act (Government of Canada 2002) due to their threatened or endangered status.

Most current testing programs for $M$. cerebralis rely on detecting the parasite in fish tissues, which often requires lethal testing of fish to detect the relevant stages of parasite development (Chiaramonte et al. 2018). Only early infections, less than 60 d, can be detected by non-lethal sampling such as caudal fin clips (American Fisheries Society-Fish Health Section 2006, Skirpstunas et al. 2006). Both microscopy (spore counts with or without initial pepsin-trypsin digestion) and molecular methods (PCR and quantitative PCR [qPCR]) for parasite identification have been used for $M$. cerebralis monitoring efforts in the USA (Arsan et al. 2007, Zielinski et al. 2010, 2011). Microscopy-based methods rely on the fish being at least $120 \mathrm{~d}$ old at the time of collection and rely on visual confirmation of the spore stage of the parasite being observed in homogenized fish tissue (Markiw $\&$ Wolf 1974). These techniques can be affected by the preservation methods used for the sample and the duration of time before the sample is analyzed. Misidentification is possible with microscopy-based techniques, as the myxospore stage shares many morphological similarities with multiple other Myxobolus species (Cavender et al. 2004, Hogge et al. 2004). To overcome the challenges associated with visual identification of $M$. cerebralis myxospores in fish tissues, DNA-based PCR and qPCR tests have been developed and employed. These tests are most frequently implemented following homogenization or a pepsintrypsin digestion of fish tissues, usually using pooled fish samples (Cavender et al. 2004, Kelley et al. 2004).

A disadvantage of relying on fish samples for M. cerebralis surveillance is that the parasite must have established in the fish population to be detected. When the parasite is newly invading an area with a small fish population, as is often the case in regions populated by species at risk of extirpation, an unacceptable proportion of the population must be lethally sampled to gain confidence that the parasite is, or is not, present. For example, in a population of 100 fish, 76 individuals would need to be sampled to 
gain a $95 \%$ level of confidence that $M$. cerebralis had been detected if present at a prevalence of $2 \%$ (Gillespie et al. 1974). This level of sampling would place a substantial burden on already threatened or endangered fish populations and would likely require continued monitoring over time. Waiting until the parasite has established in the fish population leaves preventative measures lagging behind an already entrenched population-level infection. This was noted in many of the US states combating M. cerebralis invasion, where the parasite was only detected once established in fish populations (Chiaramonte et al. 2018). It also leaves a testing gap for locations without a year-round fish population. Exclusive fish-based testing also poses challenges when used to monitor water bodies that are between regular stocking intervals or have yet to be stocked. It is crucial to determine $M$. cerebralis presence before stocking fish into a receiving waterbody. Moreover, fish collection and testing, especially when considering the vast geographic extent of available salmonid habitat, is both time consuming and costly. Hence, there is an opportunity to expand on methods used for environmental detection of other myxozoans such as Tetracapsuloides bryosalmonae (Fontes et al. 2017) and Ceratonova shasta (Hallett \& Bartholomew 2006, Hallett et al. 2012) and to build on work previously undertaken for $M$. cerebralis (Richey et al. 2018). This would support monitoring programs and researchers in detection of $M$. cerebralis during the waterborne and oligochaete stages of its life cycle.

Surveillance for parasites and invasive species using environmental samples such as water and substrate has been utilized with success to monitor for M. cerebralis (Richey et al. 2018) and other myxozoans (Hallett \& Bartholomew 2006, Hallett et al. 2012). It has also been successfully implemented for detection of other invasive species such as zebra mussels by targeting suspended larvae in water samples (Ardura et al. 2017). The first objective of this current study was to design and implement a qPCR assay to detect $M$. cerebralis life cycle stages found in substrate (myxospore) and T. tubifex, and to assess how this type of environmental monitoring can contribute to a fish-centric monitoring program. Targeting environmental life cycle stages can allow for more routine monitoring and provide data on transmission dynamics, such as seasonal peaks. As $M$. cerebralis must be established in the T. tubifex population at a site before stages that infect fish are released, this is an opportunity to detect the parasite before it has infected a significant proportion of the fish in a region.
T. tubifex is the only species of oligochaete confirmed to transmit $M$. cerebralis. However, the phylogeny of this genus of worms is likely incomplete due to the presence of cryptic species (Beauchamp et al. 2002, Liu et al. 2017, Haque et al. 2020). A T. tubifex lineage PCR test developed to assess different toxicological responses to cadmium in wild $T$. tubifex populations has also been used to demonstrate that different $T$. tubifex lineages display variable compatibility with $M$. cerebralis, with some lineages being refractory (Sturmbauer et al. 1999, Beauchamp et al. 2001, 2002, Baxa et al. 2008, Rasmussen et al. 2008, Hallett et al. 2009). The endpoint PCR test has recently been updated with a qPCR test (Richey et al. 2018). Four separate lineages, I, III, V and VI, have been found in the continental USA (Beauchamp et al. 2001), with II and IV only found in Europe (Sturmbauer et al. 1999). Compatibility between $M$. cerebralis and each lineage ranges from susceptible to infection and production of viable actinospores (I and III), to susceptible to infection but parasite development is not completed (V), to no infection at all (VI) (Beauchamp et al. 2002). Lineages II and IV have not been analyzed for $M$. cerebralis susceptibility, as the parasite is endemic in Europe and generally not of high research concern. What underpins this spectrum in compatibility with $M$. cerebralis remains unknown; however, being able to identify susceptible and resistant Tubifex populations is important for understanding invasion dynamics and attempting interventions. Moreover, developing a rapid and reliable test for assessing areas of higher parasite transmission from the worm host can indicate where the highest fish host impact may occur, thereby informing management decisions (Zendt \& Bergersen 2000, Bartholomew et al. 2005). Analyzing T. tubifex populations in novel environments for $M$. cerebralis has been a useful proxy for assessing risk to salmonid populations in locations in the USA (Bartholomew et al. 2005, McGinnis \& Kerans 2013).

The broad applicability of the lineage PCR test as a means to assess T. tubifex populations that are likely to be compatible with $M$. cerebralis is questionable for any regions where a comprehensive lineage assay assessment has not been undertaken. No largescale oligochaete assessments have been completed in Alberta or elsewhere in Canada. Variation within each lineage of $T$. tubifex with respect to their ability to propagate the parasite has been described (Rasmussen et al. 2008). For example, lineage I T. tubifex from an Alaskan population are resistant to infection (Arsan et al. 2007), while individuals mapping to the 
same lineage are able to produce actinospores in the continental USA (Beauchamp et al. 2002). To address concerns of the applicability of the T. tubifex lineage assay in assigning compatibility to M. cerebralis and to evaluate whether specific Tubifex groups displayed higher compatibility with $M$. cerebralis in Alberta, DNA barcoding was implemented. DNA barcoding of the Folmer region (Folmer et al. 1994) of the cytochrome oxidase I ( $\operatorname{cox} 1)$ gene of 567 oligochaete specimens collected from 6 different watersheds yielded 158 unique sequences, belonging to 21 genera and 37 putative species. Phylogenetic analyses suggested cryptic speciation in the Tubifex and Limnodrilus genera with 5 and 8 separate predicted species, respectively.

The objectives of this study were (1) to develop and validate a novel qPCR assay designed to facilitate detection of $M$. cerebralis from substrate and Tubifex hosts, and (2) to use this newly developed assay to test oligochaetes and substrate samples from lotic sites throughout the province of Alberta and compare to previous fish testing results. Finally, we aimed to expand our understanding of oligochaete populations that may be relevant to $M$. cerebralis transmission in Alberta using DNA barcoding. Data gathered to address these objectives were collected as part of an ongoing and comprehensive $M$. cerebralis monitoring effort that spanned $2 \mathrm{yr}$ and focused on lotic sites throughout the eastern slopes of the Alberta Rocky Mountains.

\section{MATERIALS AND METHODS}

\subsection{Sampling}

Lotic site samples were collected from 6 watersheds in Alberta (Fig. 1). Sampling occurred from March to November when the water is free from ice. Each site was visited once, with some sites being revisited if oligochaetes were successfully collected during the first attempt. Approximately 5 sites were sampled in each sub-watershed to ensure sample coverage in each area. Sites were selected based on 5 factors: the abundance of potentially susceptible salmonid species, high-risk areas for whirling disease based on stream gradient and water temperature, location of Myxobolus cerebralis hosts (e.g. high-risk stocked ponds, irrigation canals and popular fishing locations), geographic breaks related to whirling disease spread (e.g. barriers to fish movement such as dams and waterfalls) and accessibility to sites (Bartholomew et al. 2005). From 2016 to 2018, 742 unique lotic sites were sampled throughout the eastern slopes of the Rocky Mountain range in Alberta.

\subsection{Fish sample collection and DNA extraction}

Fish were collected in 2016 and 2017 from 5 to 6 lotic sites within each subwatershed, with a target of 150-175 juvenile fish total (measuring between 40 and $150 \mathrm{~mm}$ ). Fish were collected via backpack and boat electrofishing based on the size of the watercourse. Rainbow trout, brook trout, cutthroat trout and mountain whitefish were collected preferentially. Following collection, fish were stored on ice for a maximum of $4 \mathrm{~d}$ and transferred to a $-20^{\circ} \mathrm{C}$ freezer as soon as possible for a maximum of $2 \mathrm{wk}$ prior to being stored at $-80^{\circ} \mathrm{C}$ long term.

Fish were pooled in groups of 1 to 5 individuals based on species and age class. The heads were divided sagittally and separated into 2 samples. One sample was subject to homogenization, and the other was processed with a pepsin-trypsin digest (PTD) prior to DNA extraction. The homogenization protocol was based on the protocol from the Fish Health Section of the American Fisheries Society Blue Book (American Fisheries Society-Fish Health Section 2006). Briefly, fish head sections were homogenized for $60 \mathrm{~s}$ in a homogenizer in a 1:10 ratio of Dulbecco's medium. The PTD protocol was based on the guidelines outlined by Markiw \& Wolf (1974), in which heads are heated for 10-90 min and de-fleshed, leaving bone and cartilage intact, then heated for 30-120 min in $20 \mathrm{ml}$ of pepsin solution for every gram of fish tissue. The final trypsin digest is in $10 \mathrm{ml}$ of trypsin solution for every gram of starting material for $30 \mathrm{~min}$. DNA was extracted from the resulting solution from homogenization and PTD with the Qiagen Blood and Tissue Kit following the protocols for animal tissue with the exception of the final elution being $100 \mu \mathrm{l}$ instead of $200 \mu \mathrm{l}$.

\subsection{Oligochaete collection and DNA extraction}

Lotic sites where fish were collected in 2016 had corresponding oligochaete samples collected at the same locations in 2017; these are referred to as the '2016 sites' hereafter. Oligochaete samples were also collected in 2017, along with fish samples, at new sites, called '2017 sites.' In 2018, collection focused on invertebrate samples; these collection sites are the '2018 sites.'

Oligochaetes were collected using a $500 \mu \mathrm{m}$ mesh D-frame benthic kick net. At lotic sites, samplers tar- 
geted slow-moving pools with fine sediment substrates or eddies directly behind large boulders where fine sediment deposition occurs. A minimum of 5 samples were combined from the top $10 \mathrm{~cm}$ of substrate at each site. Samples were refrigerated and transported in $70 \%$ ethanol or in stream water. Samples were sorted in the laboratory, and all visible oligochaetes were individually isolated and stored in $70 \%$ ethanol at $-20^{\circ} \mathrm{C}$ until further processing. A total of 3861 oligochaetes were collected over $3 \mathrm{yr}$.

Oligochaete DNA was extracted using the DNeasy Blood and Tissue extraction kit (Qiagen), following the manufacturer's specifications with minor alterations. The ethanol in which the worms were individually stored was pipetted off prior to digestion, which took place for $2 \mathrm{~h}$. The final elution volume was $50 \mu \mathrm{l}$.

\subsection{Substrate sample collection and DNA extraction}

Substrate samples were collected starting in 2017 at the same locations at which fish were collected in 2016, referred to as the '2016 sites.' Substrate samples were collected in 2017 concurrent to fish sampling at new sites ('2017 sites'). In 2018, a small proportion of oligochaete sampling sites had corresponding substrate collected for testing ('2018 sites').

Substrate samples were collected from fine sediment habitats associated with slow-moving water (e.g. pool habitat, eddies behind boulders) and collected using a small scoop or shovel within the upper $20-30 \mathrm{~cm}$ of substrate. Substrate samples were combined from up to 3 separate locations (e.g. pools) within each site to ensure adequate coverage of the site. Samples from each location within a site were combined into 1 composite substrate sample $(\sim 50 \mathrm{ml})$, placed in a $100 \mathrm{ml}$ screw-top container and topped up with $95 \%$ ethanol or stream water.

DNA extraction from substrate samples was accomplished using the DNA Isolation Plus Kit (Norgen Biotek), and all kit protocols were followed to extract DNA from the 346 substrate samples. specific qPCR test that possessed sufficient specificity to be useful in the detection of the parasite from complex environmental matrices. Cavender et al. (2004) previously published an $18 S$-specific test; however, when this was aligned with currently available myxozoan $18 \mathrm{~S}$ sequences in silico, there appeared to be the possibility for cross-reaction with other known myxozoan species, and a likely nonagreement with the probe sequence for some $M$. cerebralis sequences (Fig. S1 in Supplement 1 [all supplementary figures] at www.int-res/articles/suppl/d145p119_supp1.pdf). When the assay of Cavender et al. (2004) was tested using a sample from a three-spined stickleback Gasterosteus aculeatus (Linnaeus 1758) that was infected with an unknown species of myxozoan parasite, a positive result was produced, further putting into question the utility of this assay if employed for environmental surveillance. As more $18 S$ sequences for myxozoan species have become available since 2004, we were able to align and analyze more species for unique regions that could serve as suitable qPCR primer and probe regions to uniquely amplify and detect $M$. cerebralis (Fig. S2). Primers were developed to amplify a $120 \mathrm{bp}$ region of $18 \mathrm{~S}$ using the real-time qPCR assay design tool from IDT (www.idtdna.com/PrimerQuest/) to select specific primer and probe sequences (Table 1). The probe used 6-carboxyfluorescein (FAM) as the reporter dye at the 5' end and Iowa Black FQ (Integrated DNA Technologies) as a quencher at the $3^{\prime}$ end. This assay was validated using plasmids containing the assay sequence and from positive control samples from purified and confirmed $M$. cerebralis myxospore samples. We also validated the test against genomic DNA isolated from $M$. squamalis, $M$. arcticus, $M$. insidiosus, M. neurobius and M. sandrae. Further, we synthesized relevant $18 S$ regions for $M$. spinacurvatura, $M$. lepomis and $M$. parvus. None of these other myxozoan targets cross-reacted with our qPCR test after 40 cycles.

To further validate the specificity of this qPCR test, the 120 bp amplicon was purified from 20 samples that were positive. The qPCR amplicons of the target region of $18 S$ were run out on an agarose gel and gel purified using the protocol described below for

\section{5. qPCR assay development and validation}

\subsection{1. qPCR assay validation}

The $18 S$ small subunit ribosomal DNA (ssrDNA) was selected as the target for the development of an $M$. cerebralis-
Table 1. qPCR primers and probe for 18S rDNA gene target for Myxobolus cerebralis. 56-FAM: 6-carboxyfluorescein; ZEN: internal quencher (Integrated DNA Technologies); 3IABkFQ: Iowa Black FQ (Integrated DNA Technologies)

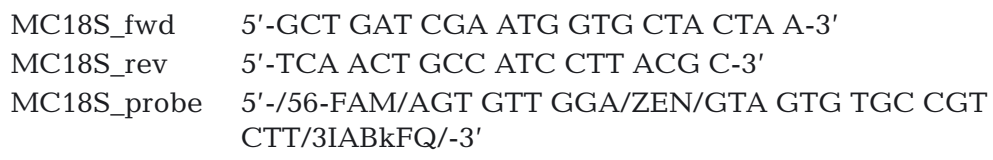


oligochaete DNA barcoding. Gel purified amplicons were sent for Sanger sequencing and compared to the online database GenBank to confirm that all 120 bp sequences aligned with M. cerebralis. All 20 amplicons shared highest identity with $M$. cerebralis GenBank entries and a $96 \%$ or greater nucleotide identity with $M$. cerebralis sequence EF370481.1, which was used for initial qPCR test design.

\subsubsection{Development of a qPCR plasmid standard}

A plasmid containing the region of the $18 S \mathrm{rDNA}$ that is targeted by the qPCR test (GenBank accession number EF370481.1, nucleotide numbers 645 to 777) was synthesized by GenScript and inserted into a puc57 vector. Plasmid preparations were transformed into TOP10 cells (Thermo Scientific) and plated on $100 \mu \mathrm{g} \mathrm{ml}^{-1}$ carbenicillin containing LB agar plates to confirm successful plasmid uptake. Plasmid purification was then accomplished with the GeneJET plasmid miniprep kit (Thermo Scientific) following the manufacturer's specifications.

\subsubsection{Standard curve and limit of detection and limit of quantification}

Purified plasmid DNA containing the specific $M$. cerebralis $18 S$ region used to generate our qPCR standard curves was quantified using a Qubit fluorometer (Thermo Scientific). Stocks of 100000 copies $\mathrm{\mu l}^{-1}$ were diluted and frozen at $-20^{\circ} \mathrm{C}$ until used. This stock was then diluted to have $50000,5000,500,50$ and 5 copies of plasmid per reaction to create the standard curve used to calculate the $18 S$ copy number in positive samples for every qPCR run. Also run in triplicate with each plate was a no-template blank and an extraction blank that consisted of distilled water that was processed using the same DNA extraction protocol described above.

Values for qPCR efficiency, slope and correlation coefficient were automatically calculated with the QuantStudio 3 software. The limit of detection (LOD) and the limit of quantification (LOQ) with 95\% confidence of our assay was determined using the probability of detection-limit of detection (POD-LOD) program with 10 replicate standard curves (Wilrich \& Wilrich 2009, Klymus et al. 2020). All standards were used to calculate LOD and LOQ.

Using DNA extracted from a known number of myxospores $(1,10,50,100$ and 200) and TAMs $(1,5$, 10, 25 and 50) suspended in PCR-grade water, we cal- culated the estimated number of DNA copies per M. cerebralis life cycle stage. Calibrating these qPCR reactions against the plasmid stock standard curve described above and adjusting for DNA extraction efficiency (assessed following the US Environmental Protection Agency method 1611 protocol described in Section 2.5.5), the estimated numbers of $18 \mathrm{~S}$ copies per myxospore (between 600 and 712) and TAM (between 7200 and 8100) were calculated. Calculated copy numbers were similar to the estimated $18 \mathrm{~S}$ rDNA copy numbers published by Kelley et al. (2004), who found 104 copies of the $18 S$ rDNA per cell. TAMs have 70 cells each, and myxospores have 6 cells each, bringing the total estimated copies of the $18 S$ gene to $\sim 7000$ per TAM and $\sim 600$ per myxospore (Kelley et al. 2004). Results from these samples were used to calculate extraction efficiency using a predicted copy number per cell of 104. Under these ideal conditions, our extraction efficiency was found to be $17.5 \pm 11.3 \%$, which is comparable to most substrate/soil DNA extraction kit efficiencies (Mumy \& Findlay 2004).

\subsection{4. qPCR reaction parameters}

All qPCR tests run in this study used IDT PrimeTime ${ }^{\circledR}$ Gene Expression Master Mix (Integrated DNA Technologies) and followed manufacturer recommendations. Reactions $(20 \mu \mathrm{l})$ were run with $5 \mu \mathrm{l}$ of extracted DNA and $250 \mathrm{nM}$ of forward/reverse primer and probe. All reactions were run in 96-well plates in a QuantStudio 3 (Thermo Scientific), using the manufacturer setting for fast cycling: $20 \mathrm{~s}$ hold at $95^{\circ} \mathrm{C}$, followed by 40 cycles of $95^{\circ} \mathrm{C}$ for $1 \mathrm{~s}$ and $60^{\circ} \mathrm{C}$ for $20 \mathrm{~s}$. Samples were prepared following standard clean qPCR workflow protocols; the master mix was stored and prepared in a pre-PCR clean room, standards and samples were added in a different room with a dedicated dead air box, and the qPCR was run in a post-amplification room where all high-copy DNA is handled and processed.

\subsubsection{Assessment of qPCR inhibition}

DNA purified from substrate samples using the Soil DNA Isolation Plus Kit (Norgen Biotek) was predominantly free of PCR inhibitors and fluorescence quenching factors. Evaluation of inhibition of the substrate qPCR reactions was accomplished using a well-established salmon testes DNA sample processing/qPCR inhibition control assessment method (Method 1611) developed by the US Environmental 
Protection Agency (US EPA 2012). We confirmed that this test does not cross react with rainbow trout, brook trout, cutthroat trout or mountain whitefish. Briefly, $20 \mathrm{mg}$ of stock salmon testes DNA (Sigma, D1626) was weighed out and placed in a sterile $50 \mathrm{ml}$ conical tube along with $20 \mathrm{ml}$ of PCR-grade water. The tube was shaken vigorously for $6 \mathrm{~h}$ to ensure homogeneous resuspension of the DNA. A $1 \mathrm{ml}$ aliquot of this stock solution was diluted to final concentration of $10 \mu \mathrm{g} \mathrm{ml}^{-1}$ using PCR-grade water. This $10 \mu \mathrm{g} \mathrm{ml}^{-1}$ stock was further diluted to a working concentration of $0.2 \mu \mathrm{g} \mathrm{ml}^{-1}$ using PCR-grade water. The qPCR primers and probes for the ribosomal RNA gene operon, internal transcribed spacer region 2 (ITS2) of chum salmon Oncorhynchus keta (Walbaum 1792) were used at final working concentrations of $1 \mu \mathrm{M}$ for each primer and $80 \mathrm{nM}$ for the probe (US EPA Method 1611). The primers and probe were added to a solution containing the qPCR reaction mixture (as described in Section 2.5.4) that included $5 \mu \mathrm{l}$ of the extracted substrate sample DNA as well as $5 \mu \mathrm{l}$ of the salmon testes DNA working solution. The final volume of this reaction was $20 \mu \mathrm{l}$, and all samples were assessed in triplicate. Thermocycling followed the protocol mentioned above.

The salmon testes DNA qPCR test reliably yields consistent cycle threshold (Ct) values of $\sim 18.5$ when run following the protocol above using a QuantStudio 3 (Thermo Scientific) qPCR instrument. Variations of $>3 \mathrm{Ct}$ from $\mathrm{Ct}$ values of 18.5 were interpreted as an inhibited sample. Any substrate DNA sample assessed as being inhibited was diluted $5 \times$ and rerun in triplicate following the protocol above; if the salmon testes DNA results shifted towards a Ct value of $\sim 18.5$, any qPCR value for the sample using the $M$. cerebralis $\mathrm{qPCR}$ was accepted and the $5 \times$ sample dilution was considered in the final DNA copy calculation. If a Ct shift back to 18.5 was not observed, the sample was recorded as inhibited and not included in further analyses.

\subsection{Testing for M. cerebralis}

\subsubsection{Substrate and oligochaetes}

The above qPCR protocol was used to test for $M$. cerebralis in 1457 unique substrate and worm samples. Samples from 2017 were stored in $70 \%$ ethanol while samples from 2018 were in stream or pond water and kept refrigerated $\left(4^{\circ} \mathrm{C}\right)$ until the samples were processed as outlined in Sections 2.3 and 2.4 to extract DNA.

\subsubsection{Fish}

In 2016, the year M. cerebralis was first discovered in Johnson Lake, Banff National Park, sampled fish were analyzed using a custom designed Government of Alberta qPCR test at the Molecular Biology Service Unit at the University of Alberta in Edmonton, Alberta. This qPCR test has not been published and was used prior to the initiation of this study. Fish samples from 2017-2018 were processed and tested using the qPCR assay developed in this study, and 50 samples were cross-validated using the Government of Alberta laboratory results for comparison to the qPCR test developed as part of this study; 3 microscopy-negative samples returned positive results using the qPCR test developed as part of this study.

\subsection{Tubifex lineage PCR}

At first, all M. cerebralis-positive worms and a selection of negative worms were run through the previously published lineage PCR assay (Sturmbauer et al. 1999, Beauchamp et al. 2001, 2002) to characterize the worm populations in Alberta based on their ability to transmit $M$. cerebralis and assess geographical differences associated with susceptible worm populations. We used a mixture of the 4 forward primers and universal reverse primer (Table 2). We adapted our protocol from (Beauchamp et al. 2002) with the following specifications: cycling parameters: initial denaturing $95^{\circ} \mathrm{C}$ for $5 \mathrm{~min} ; 35$ cycles of $95^{\circ} \mathrm{C}$ for $40 \mathrm{~s}, 44^{\circ} \mathrm{C}$ for $45 \mathrm{~s}$, $72^{\circ} \mathrm{C}$ for $1 \mathrm{~min}$; final elongation at $72^{\circ} \mathrm{C}$ for $8 \mathrm{~min}$; $250 \mathrm{nM}$ primer concentration; $10 \mu \mathrm{l}$ reaction volume; did not include the universal forward primer. The PCR products were then run through a $2.5 \%$ agarose gel and imaged using an ImageQuant LAS 4000 (GE Life Sciences). These images were then used to calculate band sizes using Gel-Analyzer (www.gelanalyzer. com). We compared these results with the species barcoding results, explained below, to confirm the accuracy of the lineage PCR test and its utility for assessing oligochaete worm populations in Alberta.

\subsection{DNA barcoding}

Sanger sequencing was used to phylogenetically characterize 609 oligochaetes collected as part of this study. Partial cox1 sequences in the Folmer region were amplified by PCR using the DNA extracted as described above in $10 \mu \mathrm{l}$ reaction volumes with IDT PrimeTime master mix and $250 \mathrm{nM}$ concentration of 
Table 2. Name and nucleotide sequences for the $16 S$ rDNA Tubifex sp. lineage PCR assays. Anticipated PCR band sizes and citations for each assay are also shown

\begin{tabular}{|lllll|}
\hline Lineage & \multicolumn{1}{c}{ Primer } & \multicolumn{1}{c|}{ Sequence (5'-3') } & Band size & Citation \\
\hline & $\begin{array}{l}\text { 16sbr- universal } \\
\text { reverse primer }\end{array}$ & CCG GTC TGA ACT CAG ATC ACG T & & Beauchamp et al. (2001) \\
I & L1- forward & GGA CAA ACG AGA ATA TC & 196 & Sturmbauer et al. (1999) \\
II & L2- forward & TGT AGG CTA GAA TGA AC & 400 & Sturmbauer et al. (1999) \\
III & L3- forward & TCA CCC CCA AAC TAA AAG ATA T & 215 & Sturmbauer et al. (1999) \\
IV & L3 & TCA CCC CCA AAC TAA AAG ATA T & 320 & Sturmbauer et al. (1999) \\
& L5 & AAG AAG CTT AAA TAA ACG & 215 & Sturmbauer et al. (1999) \\
V & L5- forward & AAG AAG CTT AAA TAA ACG & 320 & SA \\
\hline
\end{tabular}

the LCO 1490 and HCO 2198 primers (Folmer et al. 1994) and $4 \mu \mathrm{l}$ of extracted DNA. The thermocycler protocol was: initial denaturing at $95^{\circ} \mathrm{C}$ for $5 \mathrm{~min}$; 35 cycles of $95^{\circ} \mathrm{C}$ for $40 \mathrm{~s}, 44^{\circ} \mathrm{C}$ for $45 \mathrm{~s}$ and $72^{\circ} \mathrm{C}$ for $1 \mathrm{~min}$; final elongation at $72^{\circ} \mathrm{C}$ for $8 \mathrm{~min}$.

The amplicons were run in a $1 \%$ agarose gel and extracted using the GeneJet Gel Extraction kit (Thermo Scientific). Purified amplicons were sent to Macrogen (Korea) for Sanger sequencing; the same primers for the PCR reaction were used for sequencing both forward and reverse sequences.

\subsection{Sequence alignments}

All cox1 sequences were checked for quality by viewing chromatograms and quality scores in 4 peaks (Nucleobytes) software. Primer regions were trimmed and sequences transferred to Geneious Prime 2019 (https://www.geneious.com) to align the forward and reverse sequences. Because 27 of the barcoded oligochaetes had a poor quality forward or reverse sequence, we used a single sequence instead of an alignment. Each consensus or individual resulting sequence was then compared using BLASTn against the NCBI GenBank database. A representative sequence from every species with over $80 \%$ match was used to align to each consensus sequence and produce a percent identity matrix. A conservative $5 \%$ was used as the match cut-off value to make an initial species identification as published literature values vary (Bely \& Wray 2004, Achurra et al. 2011). If no match was found within this cut-off, the next highest match was used. After accounting for poor sequence quality, 567 sequences were included in the final assessment. Completed and in-frame cox 1 sequences were batch uploaded under GenBank accession numbers MW703510-MW703546 (see Table S3 in Supplement 1 for detailed GenBank accession numbers of a representative species).

\subsection{Phylogenetic reconstruction and species determination}

Alignments were trimmed to the shortest sequence length prior to any analysis. MegaX was used for model testing using nucleotide substitution for each group of sequences. Bayesian inference (BI) reconstructions were made using the Mr. Bayes plug-in (Huelsenbeck \& Ronquist 2001, Ronquist \& Huelsenbeck 2003) in Geneious Prime 2019 with a burn-in of 100000 , a chain length of 1000000 and subsampling frequency of 200. Maximum likelihood (ML) analyses were run in the PhyML plug-in (Guindon et al. 2010) for separate genus-level analysis. The settings used were: 200 bootstraps, proportion of invariable sites was fixed at 0 , the number of substitution rate categories was 4 , the gamma distribution parameter was set to 'estimated,' and 'topology/ length/rate' was selected to be optimized. Substitution model selection was the same for both BI and ML analyses and is described in each section below.

\subsubsection{Phylogenetic tree analysis}

A total of 157 unique sequences found in our study were aligned with the outgroup Hirudo medicinalis (HQ333519.1); the alignment was 586 bp long. GTR + invgamma was the best-supported nucleotide substitution model available in the MrBayes plug-in in Geneious for BI analyses. Next, 18 unique sequences belonging to the genus Tubifex were assessed together in BI and ML analyses, via Automatic Barcode Gap Discovery (ABGD) and using p-distance along with representatives from GenBank to look for any cryptic speciation at a finer scale. The same assessments were done with 49 unique sequences from the genus Limnodrilus.

We identified 25 sequences as falling within the genus Tubifex: 18 from this study and 7 from Gen- 
Bank. The alignment was $555 \mathrm{bp}$ long, and H. medicinalis (HQ333519.1) was used as the outgroup. HKY85 + invgamma was the best-supported nucleotide substitution model available in the MrBayes and PhyML plug-ins in Geneious.

We also identified 55 sequences as falling within the genus Limnodrilus: 49 from this study and 6 from GenBank. The alignment was 552 bp long, and $H$. medicinalis (HQ333519.1) was used as the outgroup. HKY85 + invgamma was the best-supported nucleotide substitution model available in the $\mathrm{Mr}$ Bayes and PhyML plug-ins in Geneious.

\subsection{2. $\mathrm{ABGD}$}

ABGD (Puillandre et al. 2012) was used to confirm the natural breaks in the phylogenies and assess the previous species cut-off of $5 \%$. It was run online and all default values were used $\left(p_{\min }: 0.001 ; p_{\max }: 0.01\right.$; Steps: 10 ; X [relative gap width]: 1.5 ; Nb bins: 20 ; distance measurement: Jukes-Cantor [JC69]).

\subsubsection{P-distances}

In addition to ABGD, we used p-distances to confirm the separation of taxa in the genera of Tubifex and Limnodrilus, as many of our sequences within each of these genera had great enough diversity to suggest cryptic speciation. We used this more indepth analysis to confirm these species divisions. P-distances were calculated in MegaX, calculating within and between-group distances, using all preset functions.

\section{RESULTS}

\section{1. qPCR assay development}

The $95 \%$ confidence interval LOD was calculated to be 7.4 copies of $18 S$ rDNA per reaction, and the LOQ was calculated to be $22.518 S$ copies per reaction. The average efficiency of the qPCR reaction across 15 standard curve replicates was $0.92(\mathrm{SD}=$ $0.11)$. All reactions had correlation coefficients $\left(\mathrm{R}^{2}\right)$ of 0.99 . The slope of the mean standard curve was -3.53 (Fig. S3). Each DNA sample was run in triplicate, and all 3 replicates had to have amplification within 37 cycles ( $\sim 5$ copies) to be considered a positive sample. The reported copy number is a mean of the 3 replicates. Our estimated $18 S$ copy number for myxo- spores is between 600 and 712 and between 7200 and $810018 S$ copies per TAM. Assuming TAMs have 70 cells and myxospores 6 , our estimated number of 18S copies per Myxobolus cerebralis cell is 100-118.

\subsection{Three year monitoring program results}

A total of 1479 substrate and oligochaete samples from 688 sites were analyzed using the $M$. cerebralis qPCR assay developed as part of this study. This included 1133 individual oligochaete samples and 346 substrate samples. Of these, 1406 samples were negative for $M$. cerebralis, 30 samples were positive, and 12 were 'suspect,' i.e. tests where either the triplicates displayed variance of $>1 \mathrm{Ct}$ or the calculated copy number was close to the LOD of the test and the sample could not be re-run to confirm the result. The positive results originated from 11 unique sites, outlined by sample type and watershed in Table 3 . Test results from all sites can be found in Table S1 in Supplement 2 at www.int-res/articles/suppl/d145 p119_supp2.xlsx. Of the sites where worms tested positive for $M$. cerebralis, we found a $12-23 \%$ tubificid infection prevalence, which is much higher than previously observed data, suggesting the percent that sheds TAMs in an infected population ranges between 1.2 and $6.8 \%$ (Rognlie \& Knapp 1998, Zendt \& Bergersen 2000).

In total, $73 \%$ of the positive results came from the southern part of the province (Oldman, Bow and Red Deer watersheds). However, worms were found to be M. cerebralis-positive by qPCR in watersheds where the parasite had previously not been detected by fish testing, at sites located in the Athabasca (2 sites, 7 worms) and Peace River (1 site, 1 worm) watersheds (Table 3).

If we assume that a patently infected worm should present estimated DNA copy numbers that align with the presence of at least 1 TAM ( 6000 copies), then only the Crowsnest River had worms that were patently infected after adjusting for extraction efficiency (Table 3).

\subsection{Sample matrix comparison}

\subsubsection{6 results}

Fish were collected in 2016 and corresponding substrate and invertebrate samples were taken a year later at 110 sites. Of these 110 sites, 5 were positive for M. cerebralis. Three sites yielded positive substrate 
Table 3. Substrate and worm positive qPCR test results from the 18S_MC assay. Mean 18S rDNA copy number of 3 replicate qPCR reactions is presented along with standard deviation

\begin{tabular}{|c|c|c|c|c|c|c|c|}
\hline \multirow[t]{2}{*}{ Site ID } & \multirow[t]{2}{*}{ Year } & \multirow[t]{2}{*}{ Type } & \multirow{2}{*}{$\begin{array}{l}\text { Gene copy } \\
\text { count (SD) }\end{array}$} & \multirow[t]{2}{*}{ Location } & \multirow[t]{2}{*}{ Watershed } & \multicolumn{2}{|c|}{ Coordinates } \\
\hline & & & & & & Latitude $\left({ }^{\circ} \mathrm{N}\right)$ & Longitude $\left({ }^{\circ} \mathrm{W}\right)$ \\
\hline \multirow[t]{10}{*}{054} & \multirow[t]{10}{*}{2016} & Worm & $87(15.8)$ & \multirow[t]{10}{*}{ Crowsnest River } & \multirow[t]{10}{*}{ Old Man River } & \multirow[t]{10}{*}{49.5498} & \multirow[t]{10}{*}{114.2954} \\
\hline & & Worm & 48607 (762.7) & & & & \\
\hline & & Worm & $15(9.6)$ & & & & \\
\hline & & Worm & $87(7.0)$ & & & & \\
\hline & & Worm & $1422774(11026.3)$ & & & & \\
\hline & & Worm & $63837(1835.5)$ & & & & \\
\hline & & Worm & $13(5.4)$ & & & & \\
\hline & & Worm & $11(4.4)$ & & & & \\
\hline & & Worm & $31(4.1)$ & & & & \\
\hline & & Substrate & $2843(391.5)$ & & & & \\
\hline 062 & 2016 & Substrate & $9(3.8)$ & Crowsnest River & Old Man River & 49.5848 & 114.2049 \\
\hline \multirow[t]{7}{*}{063} & \multirow[t]{7}{*}{2016} & Worm & $28(10.7)$ & \multirow{7}{*}{ Crowsnest River } & \multirow[t]{7}{*}{ Old Man River } & \multirow[t]{7}{*}{49.5936} & \multirow[t]{7}{*}{114.1704} \\
\hline & & Worm & $9203676(271480.7)$ & & & & \\
\hline & & Worm & $23(5.2)$ & & & & \\
\hline & & Worm & $43(6.7)$ & & & & \\
\hline & & Worm & 49 (9.8) & & & & \\
\hline & & Worm & $17(2.3)$ & & & & \\
\hline & & Worm & $29(7.6)$ & & & & \\
\hline 086 & 2016 & Substrate & $12(3.1)$ & Dogpound Creek & Red Deer River & 51.4161 & 114.4994 \\
\hline 237 & 2016 & Worm & $10(4.5)$ & Fallentimber Creek & Red Deer River & 51.6232 & 114.7274 \\
\hline 015 & 2017 & Worm & $291(57.7)$ & Moon Creek & Peace River & 54.4557 & 118.0307 \\
\hline \multirow[t]{5}{*}{056} & \multirow[t]{5}{*}{2017} & Worm & $5(0.6)$ & \multirow[t]{5}{*}{ Athabasca River } & \multirow[t]{5}{*}{ Athabasca River } & \multirow[t]{5}{*}{54.1502} & \multirow[t]{5}{*}{115.3401} \\
\hline & & Worm & $17(2.8)$ & & & & \\
\hline & & Worm & $105(3.9)$ & & & & \\
\hline & & Worm & $6(1.1)$ & & & & \\
\hline & & Worm & $8(2.0)$ & & & & \\
\hline \multirow[t]{2}{*}{032} & \multirow[t]{2}{*}{2018} & Worm & $8(3.0)$ & \multirow[t]{2}{*}{ Taylor Creek } & \multirow[t]{2}{*}{ Athabasca River } & 53.0047 & 117.0131 \\
\hline & & Worm & $19(4.1)$ & & & & \\
\hline 258 & 2018 & Substrate & $560(79.2)$ & Crowsnest River & Old Man River & 49.5615 & 114.2575 \\
\hline & & Worm & 389417 (15 462.3) & & & & \\
\hline
\end{tabular}

results (Crowsnest River 054, 062 and Dogpound Creek), and 3 had positive worms (Crowsnest River 054, 063 and Fallentimber Creek); these samples were all collected from watersheds (Bow River and Oldman River) that had previously tested positive via fish analysis (Table 3). Only 1 site (054) produced both positive substrate and oligochaetes in the Crowsnest River. These positive worms $(n=17)$ had an average of 631726 estimated copies of the $18 S$ rDNA with a range of 10 to 9203676 . The average substrate $18 S$ copy number per reaction was much lower at 955, with a range of 5-2843 copies per reaction.

\subsubsection{7 results}

In 2017, M. cerebralis-positive fish were found in 56 of 166 sites from the Red Deer River, North Saskatchewan River, Bow River and Oldman River watersheds. Out of 166 sites where oligochaetes and substrate were collected in 2017, no sites had positive substrate and 2 sites had positive worms. These sites were found in the most northern sampled watersheds, Athabasca and Peace River, both of which were negative for $M$. cerebralis when assessed by fish testing. The average number of $18 S$ rDNA copies per reaction in the positive worms $(n=6)$ was 72 , with a range of 5-291 (Table 3). These sites represent an interesting example of where the parasite may be establishing in the worm population as its range expands northward in the province but has not reached a detectable level in the fish population or is not being consumed by species of oligochaete that are compatible with $M$. cerebralis.

\subsubsection{8 results}

In 2018, there was a single site from which a positive substrate sample was collected. However, fewer 
substrate samples were collected in 2018 compared to 2017 ; $45 / 383$ sites had substrate collected. Two sites yielded positive oligochaete results, one located in the North Saskatchewan River and one in the Bow River watershed; the latter location had the corresponding positive substrate sample, but no substrate sample was collected in the former (Table 3). The average number of $18 \mathrm{~S}$ rDNA copies per reaction in the positive worms $(\mathrm{n}=3$ ) was 129811 , with a range of 8-389417. The positive substrate sample had an $18 S$ copy number of 560 . No fish were collected in 2018 for comparison.

\subsection{DNA barcoding of oligochaetes in Alberta}

\subsubsection{Unbiased oligochaete barcoding}

Unbiased barcoding of 567 oligochaete samples throughout Alberta in 2017 led to the identification of 157 unique sequences. BLASTn analysis of the cox1 sequences led to the assignment of 37 unique predicted species belonging to 21 predicted genera (Table S2 in Supplement 1). Of the total sequences assessed, $42.3 \%(240 / 567)$ belonged to a Tubifex sp. complex, and $41.8 \%(237 / 567)$ belonged to a Limnodrilus sp. complex, which are addressed in more detail below. The DNA barcoding results were separated based on the watersheds from which they were sampled (Table S3) (Fig. 2). Oligochaete populations from each watershed in the study were relatively consistent with respect to predicted species composition. Each watershed in the study contained at least 1 Tubifex sp. (group T3), Limnodrilus sp. (groups L1, L5 and L7), with the exception of the Peace River watershed, likely due to its small sample size. Two Tubifex sp., T1 and $\mathrm{T} 2$, were found in higher numbers in all watersheds with 2 exceptions; T1 was not found in the Red Deer River basin and T2 was not found in the Old Man River basin (Fig. 2).

\subsubsection{Tubifex sp.}

BI and ML analyses agreed on separation of Tubifex sp. into 5 groups (numbered T1-T5) and tree topology with good statistical support (Fig. 3). Analy-

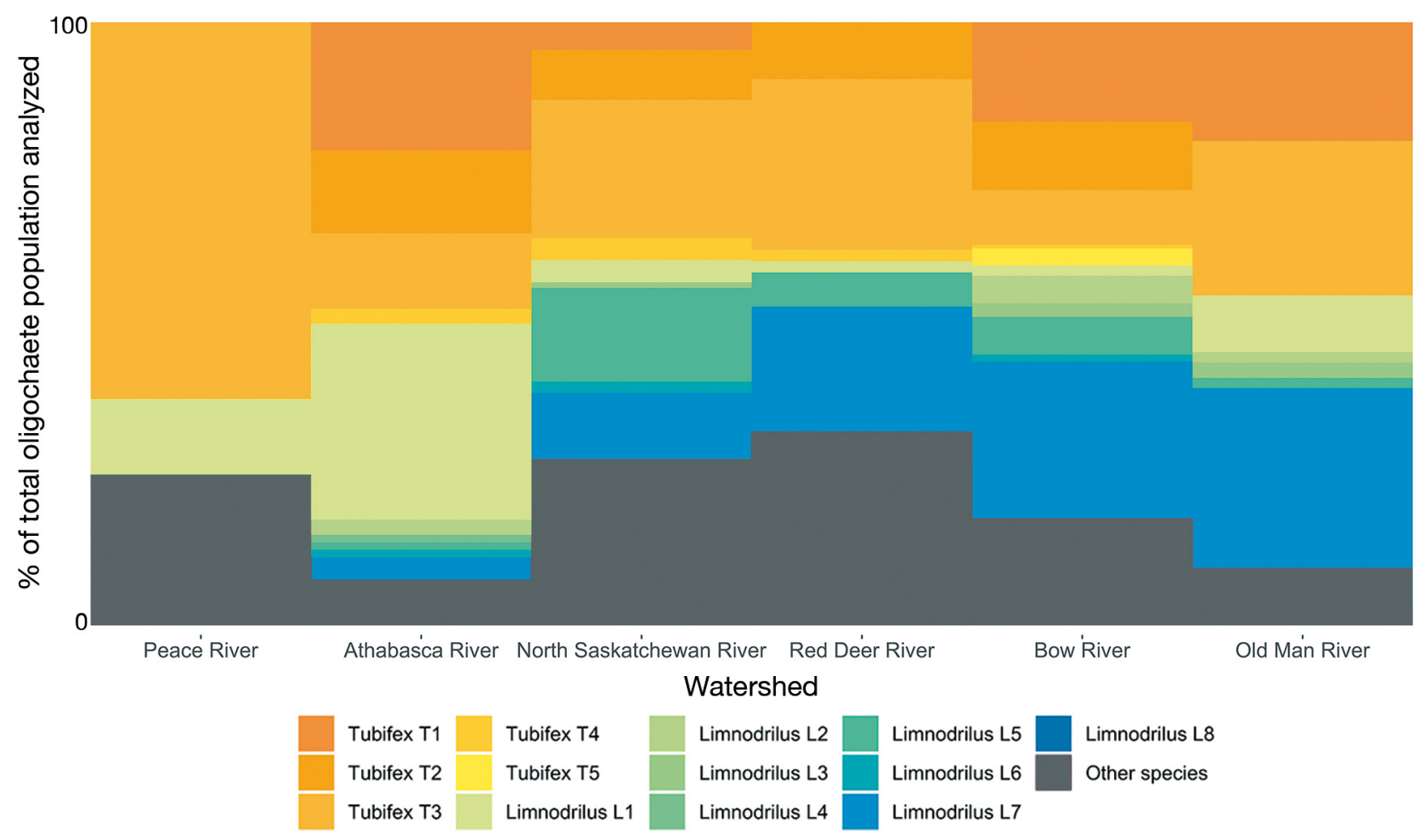

Fig. 2. Freshwater oligochaete populations at each of the 6 study watersheds, as distinguished by cox1 barcoding. A substantial proportion of the total population at each site is comprised of Tubifex and Limnodrilus. The actual number of worms identified in each watershed within each taxonomic group, and the taxonomic groups that comprise 'other species', can be found in Table S3 in Supplement 1 


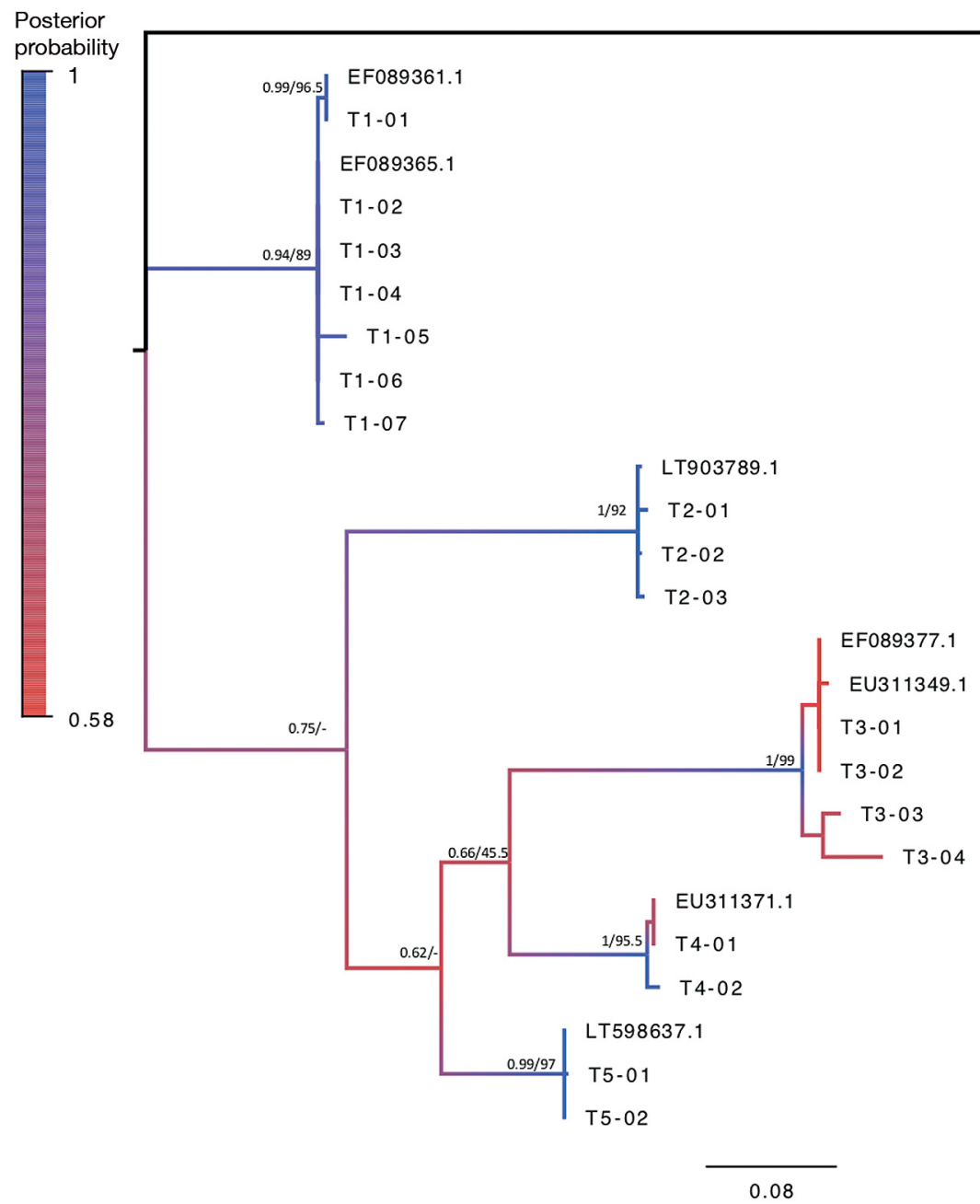

sis revealed 5 distinct groupings for species cut-off based on the ABGD results (JC $\left.p_{\max }=0.0001\right)$ with an interspecific divergence of $6-13 \%$. P-distances confirmed these 5 groups, with no groups having intraspecific diversity high enough to suggest any further speciation $(0-3 \%)$ (Table 4$)$.

\subsubsection{Limnodrilus sp.}

BI and ML analyses agreed on species separation into 8 groups (numbered L1-L8) and tree topology with good statistical support (Fig. 4). Results showed 8 distinct groups for species cut-off based on the ABGD results $\left(\mathrm{JC} p_{\max }=0.0001\right)$ with interspecific divergence of $11-13 \%$. P-distances confirmed the 8 groups, with no groups having high enough intraspe- cific diversity to suggest further speciation $(0-7 \%)$ (Table 5).

Certain cox1 sequences that matched to L. udekemianus via GenBank did not group with the other Limnodrilus sp. complex found in this study (Fig. S4).

Fig. 3. Maximum-likelihood phylogeny of Tubifex tubifex based on cox1. Posterior probabilities $>50$ (also reflected in branch color, with blue being highest) and bootstrap values $>50$ are reported at the nodes. GenBank accession numbers are given for one sequence in each clade not from this study, identified as T. tubifex. This phylogeny shows 5 well-supported groups (T1-T5) within this species

Table 4. Number of base substitutions per site from averaging over all sequence pairs between Tubifex sp. groups are shown below the diagonal. Standard error estimates are shown above the diagonal. Average within-group divergence is given on the diagonal. Analyses were conducted using the maximum composite likelihood model and involved 25 nucleotide sequences. In total, 557 positions were included in the final dataset. Diagonal is highlighted in bold

\begin{tabular}{|llllll|}
\hline & Group T1 & Group T2 & Group T3 & Group T4 & Group T5 \\
\hline Group T1 & $\mathbf{0 . 0 1}$ & 0.177 & 0.16 & 0.153 & 0.162 \\
Group T2 & 0.289 & $\mathbf{0 . 0 3}$ & 0.139 & 0.162 & 0.184 \\
Group T3 & 0.26 & 0.212 & $\mathbf{0 . 0 1}$ & 0.108 & 0.168 \\
Group T4 & 0.248 & 0.239 & 0.16 & $\mathbf{0}$ & 0.155 \\
Group T5 & 0.28 & 0.297 & 0.254 & 0.239 & $\mathbf{0 . 0 1}$ \\
\hline
\end{tabular}




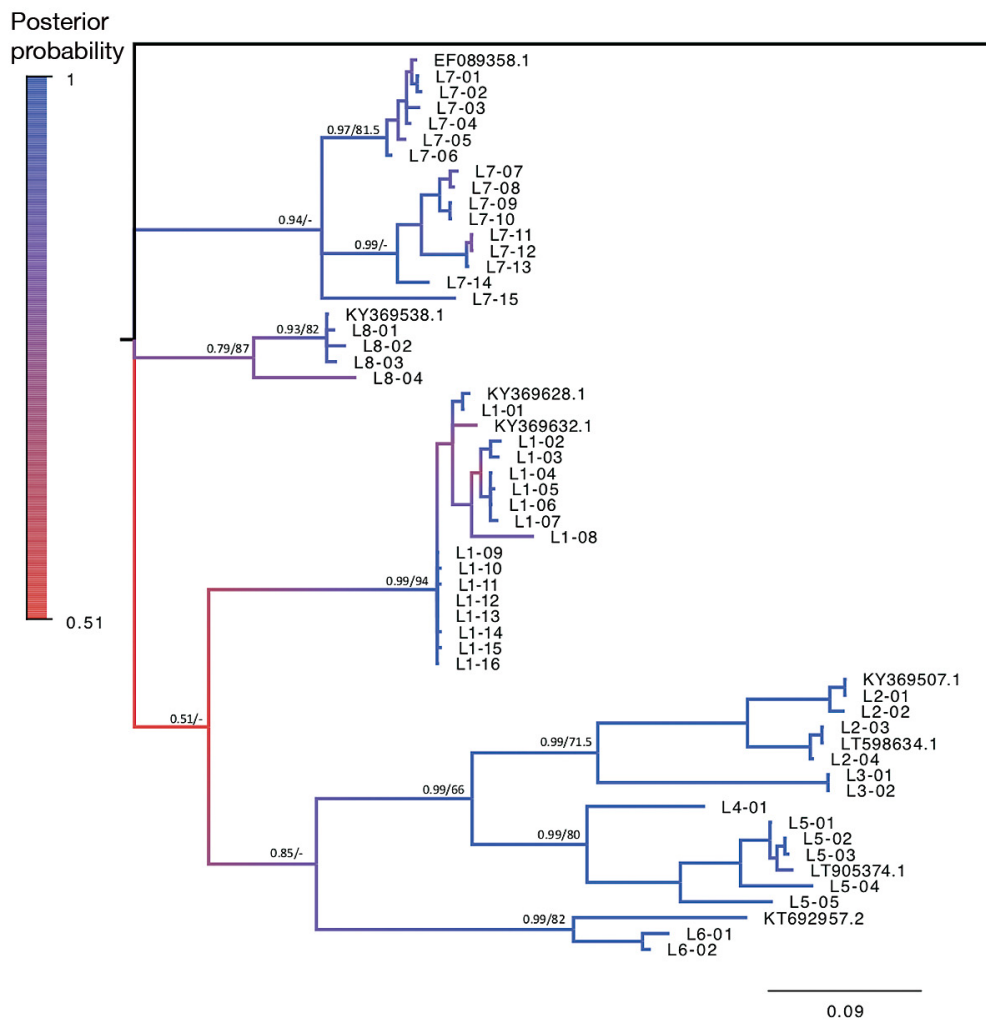

Fig. 4. Maximum-likelihood phylogeny of Limnodrilus sp. based on cox1. Posterior probabilities $>50$ (also reflected in branch color, with blue being highest) and bootstrap values $>50$ are reported at the nodes. GenBank accession numbers are given for one sequence not from this study in each clade, identified as Limnodrilus sp. This phylogeny shows 8 well-supported groups (L1-L8) within this species

Table 5. Number of base substitutions per site from averaging over all sequence pairs between Limnodrilus sp. groups are shown below the diagonal. Standard error estimates are shown above the diagonal. Average within-group divergence is given on the diagonal. Analyses were conducted using the maximum composite likelihood mode and involved 54 nucleotide sequences. In total, 552 positions were included in the final dataset; there were too few sequences available within Group 4 for an intragroup comparison (NA). Diagonal is highlighted in bold

\begin{tabular}{|lcccccccc|}
\hline & Group L1 & Group L2 & Group L3 & Group L4 & Group L5 & Group L6 & Group L7 & Group L8 \\
\hline Group L1 & $\mathbf{0 . 0 2}$ & 0.036 & 0.043 & 0.029 & 0.034 & 0.039 & 0.027 & 0.037 \\
Group L2 & 0.237 & $\mathbf{0 . 0 6}$ & 0.036 & 0.042 & 0.045 & 0.031 & 0.041 & 0.028 \\
Group L3 & 0.286 & 0.241 & $\mathbf{0}$ & 0.036 & 0.043 & 0.037 & 0.045 & 0.036 \\
Group L4 & 0.205 & 0.268 & 0.234 & NA & 0.021 & 0.038 & 0.034 & 0.035 \\
Group L5 & 0.24 & 0.3 & 0.273 & 0.151 & $\mathbf{0 . 0 6}$ & 0.044 & 0.036 & 0.038 \\
Group L6 & 0.265 & 0.217 & 0.247 & 0.254 & 0.293 & $\mathbf{0 . 0 2}$ & 0.04 & 0.026 \\
Group L7 & 0.189 & 0.255 & 0.285 & 0.225 & 0.246 & 0.267 & $\mathbf{0 . 0 7}$ & 0.038 \\
Group L8 & 0.25 & 0.198 & 0.239 & 0.233 & 0.263 & 0.185 & 0.25 & $\mathbf{0 . 0 5}$ \\
\hline
\end{tabular}

The L. udekemianus (GenBank accession number LT598633.1) sequence along with 3 additional Limnodrilus sp. sequences also included in the analysis, which were submitted as part of the same study, represent specimens from Europe. Thus, it is unclear if the observed sequence differences are due to a phylogenetic difference between the oligochaete populations of North America and Europe, or misidentification of this group of Limnodrilus specimens in GenBank, which is possible given the challenges with oligochaete identification (Fig. S4).

\subsection{Assessment of DNA-barcoded oligochaetes for $M$. cerebralis using qPCR}

M. cerebralis was detected in 3.7\% (21/567) of all the oligochaetes analyzed using the qPCR test developed as part of this study. $M$. cerebralis was detected in $4.6 \%$ of the oligochaetes that were phylogenetically assigned to the genus Tubifex (11/240) and $4.2 \%$ of the oligochaetes assigned to the genus Limnodrilus (10/237). We cannot confirm whether these are patent infections, in which worms are actively shed- 
ding TAMs, or if these detections were pre-patent in nature; however, only oligochaetes that were phylogenetically assigned to the genus Tubifex reached estimated $18 S$ rDNA copy numbers that were consistent with the $\sim 7100-8200$ estimated copy numbers associated with single TAMs.

Only Limnodrilus sp. L1 ( $\mathrm{n}=49 ; 21 \%$ of total Limnodrilus analyzed) and L7 ( $\mathrm{n}=118 ; 50 \%$ of total Limnodrilus analyzed) and Tubifex sp. T1 (n = 74; $31 \%$ of total Tubifex analyzed) and T3 ( $\mathrm{n}=101 ; 42 \%$ of total Tubifex analyzed) had positive $M$. cerebralis test results (Table S2). The calculated DNA copy numbers from the positive qPCR tests ranged from 11 to 87 for Tubifex sp. T1, 15 to 9203676 for Tubifex sp. T3. Limnodrilus sp. L1 had a range of 6 to 105 and Limnodrilus sp. L7 had a range of 5 to 29. The lower overall copy number in Limnodrilus sp. and Tubifex sp. T1 indicates that it is likely these species can consume myxospores and then test positive for $M$. cerebralis, but we do not know at this time if they can produce viable actinospores. The very high gene copy numbers observed in Tubifex sp. T3 are suggestive of a patent infection.

\subsection{Lineage PCR and barcoded species comparisons}

Tubifex lineages I and III are known to transmit M. cerebralis. Lineages IV and V are described as being not susceptible to $M$. cerebralis infection, and lineages II and IV are considered to be only endemic in Europe. The oligochaete samples that returned positive qPCR test results for $M$. cerebralis were assessed for their T. tubifex lineage status. We found most worms either did not yield any bands in the end point lineage PCR assay, or the band sizes did not correspond to a published band size reported for the lineage assay. Expected PCR band sizes based on previously published results are found in Table 2, and lineage assay results from oligochaetes tested as part of our survey can be found in Table S2.

Oligochaetes identified as Tubifex via cox1 barcoding, and which were also confirmed to be $M$. cerebralis-positive by qPCR, produced results representative of lineages I, II, III and V, as well as a single band around $240 \mathrm{bp}$, which does not match with any published lineage, or no bands at all (Fig. 5). Additionally, Tubifex belonging to the same taxonomic group, based on cox1 barcoding, produced multiple lineage PCR results (Table S2). The Limnodrilus sp. worms that were qPCR-positive for $M$. cerebralis did not yield any bands in the lineage PCR assay. How-

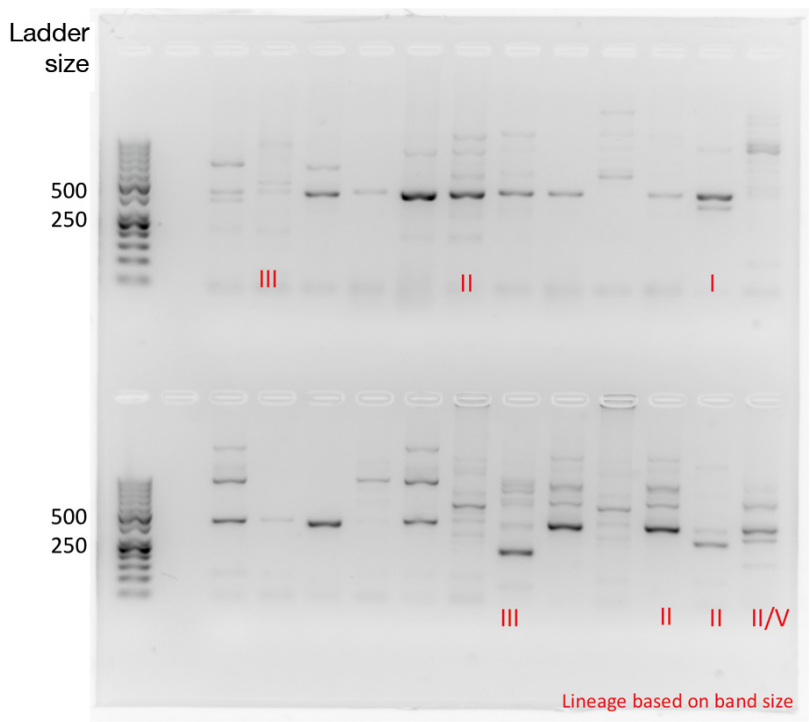

Fig. 5. Representative $2.5 \%$ agarose gel electrophoresis of PCR-amplified genomic DNA from oligochaete worms (Tubifex) in Alberta, Canada, using 16S rDNA lineagespecific primers. The left lane shows a DNA standard ladder (50 bp). Lineage results are indicated in red

ever, other closely related Limnodrilus specimens, that were negative for $M$. cerebralis, but from the same OTU, yielded a 240 bp band. A worm in OTU 111, which when compared to the GenBank database shared the highest nucleotide identity to Aktedrilus sp., yielded a $240 \mathrm{bp}$ band in the lineage PCR. One sample, which was identified as Octolasion cyaneum with $98.7 \%$ nucleotide identity in $\operatorname{cox} 1$, yielded a banding pattern that matched both lineages II and $\mathrm{V}$ T. tubifex. Two worms from OTU 125 identified as Lumbriculida sp. and OTU 156 identified as Marionina riparia produced a banding pattern that matched T. tubifex lineage II.

\section{DISCUSSION}

During this 3 yr study, we collected 3861 oligochaetes and 346 substrate samples from 688 sites in Alberta, spanning 6 different watersheds. Over 1500 of these samples were analyzed using a novel qPCR test designed to facilitate detection of Myxobolus cerebralis from host and environmental samples. The results of this study were used to assess the distribution of $M$. cerebralis in Alberta, Canada, and to complement existing fish-based monitoring programs. Our results align with the findings of traditional $M$. cerebralis fish testing, with positive environmental detections in the southern watersheds of Alberta, and highlight the advantages of incorporating multi- 
ple sample matrices into monitoring efforts by indicating low parasite prevalence in northern Alberta watersheds where fish samples have been negative. These results suggest it is possible to detect the parasite in the oligochaete host population prior to positive results in the fish population, thereby predicting potential future transmission sites. Given that the oligochaete host is less mobile than the fish and is also the host from which the fish-infectious stage emerges highlights the utility of including oligochaete monitoring into surveillance programs for M. cerebralis.

The Crowsnest River returned the most positive substrate and Tubifex samples. Four unique sampling sites along the Crowsnest River yielded either positive substrate, positive Tubifex or both. Moreover, many of the Tubifex from this location were assessed by our qPCR assay to be heavily infected by $M$. cerebralis, as evidenced by the fact that 5 Tubifex displayed estimated $M$. cerebralis $18 S$ copy numbers above 45000 , with one reaching nearly 1.5 million. Based on the results of the environmental survey, the sites identified in Table 3 from the Crowsnest River, Dogpound Creek and Fallentimber Creek could serve as useful long-term baseline monitoring sites from known M. cerebralis-positive locations. Additionally, Moon Creek (Peace River) and Athabasca River/Taylor Creek represent appealing locations for persistent $M$. cerebralis surveillance efforts, as these waterbodies have yet to yield an $M$. cerebralispositive fish.

Once infected by $M$. cerebralis, $T$. tubifex maintain the infection throughout their lives (Gilbert \& Granath 2001). Thus, these worms can serve as an important and useful target for monitoring efforts. While the prevalence of worms actively shedding TAMs in natural populations is reported as usually being quite low, between 1.2 and $6.8 \%$ (Rognlie \& Knapp 1998, Zendt \& Bergersen 2000), we found positive detections in $12-23 \%$ of the worms using our $M$. cerebralis qPCR test, likely because the sensitivity of qPCR allows for the detection of pre-patent infections or worms that are not currently actively releasing TAMs. We were able to detect $M$. cerebralis using $\mathrm{qPCR}$ in a previously thought noncompatible worm host, Limnodrilus sp., but these worms yielded an overall lower $18 \mathrm{~S}$ copy number than that observed in the known Tubifex sp. host, suggesting they had consumed myxospores but had not developed a patent infection. This is an important distinction because to appropriately manage the parasite and protect fish populations, the correct oligochaete host has to be targeted, as it produces the parasite stage infective to fish. A worm testing positive for $M$. cerebralis that is not able to carry a patent parasite infection is of less concern for managing disease outbreaks, but is also useful when considering monitoring efforts, which are typically focused on positive/negative results rather than confirming completion of the parasite life cycle. In addition, $M$. cerebralis must be established in the worm population before it can be transmitted to the fish population, providing an avenue for early detection as a complement to fish testing.

An additional dimension of $M$. cerebralis invasion that can be gauged by incorporating oligochaete sampling is the assessment of the proportion of compatible T. tubifex lineages present in the environment (Sturmbauer et al. 1999, Beauchamp et al. 2001, 2002, Baxa et al. 2008, Rasmussen et al. 2008). Our intention was to assess tubificid lineage as part of this study; however, we found inconsistencies when implementing the published PCR-based T. tubifex lineage assay (Sturmbauer et al. 1999, Beauchamp et al. 2001, 2002). Many lineage PCR results did not fit expectations based on previously published lineages, with the majority of analyzed oligochaetes producing a band size pattern inconsistent with any published band sizes for this test, or no band at all. Moreover, worms that tested positive for $M$. cerebralis based on the qPCR test did not consistently return results indicative of a previously determined susceptible lineage (I or III) (Beauchamp et al. 2002). In fact, the worm that displayed the highest estimated DNA copy number for $M$. cerebralis belonged to taxonomic group 3 of our Tubifex phylogeny but was not assigned to any T. tubifex lineage in the lineage PCR. These inconsistencies lead us to believe that the lineage test may not be reliable for assessing M. cerebralis susceptibility in T. tubifex populations in Alberta. Unfortunately, the more recently published qPCR lineage assay (Richey et al. 2018) was not available when this study was initiated. Thus, to take a more unbiased approach to oligochaete identification, we opted to utilize DNA barcoding to assess oligochaetes found in the substrate of rivers where $M$. cerebralis was thought to have invaded in Alberta.

This study presents the first large-scale assessment of freshwater sedimentary oligochaete populations throughout the eastern slopes of the Alberta Rocky Mountain range. During the 2016/2017 sampling years, we took an unbiased approach to oligochaete barcoding, individually sequencing cox 1 for any oligochaete found from a sampling site. This approach was taken to ensure that we would be able to capture 
information related to the density of $T$. tubifex with respect to other oligochaetes at any study site. We hypothesized that we might observe differences in the oligochaete populations defined by watershed, waterbody or geography that could create an ecological barrier that could limit the spread of $M$. cerebralis in Alberta. Having advanced knowledge of potential sites of new transmissions can facilitate the implementation of management decisions to help protect vulnerable fish populations or reduce the establishment of $M$. cerebralis into novel areas (Treb itz et al. 2017). However, our barcoding results indicate that potential $M$. cerebralis-susceptible Tubifex hosts are abundant in all Alberta watersheds sampled, suggesting that all are potential sites of M. cerebralis transmission.

Previous studies focused on oligochaete taxonomy in Canada have mainly focused on morphology (Dash 1970, Nurminen 1973, Brinkhurst 1978) or Tubifex sp. utility for ecotoxicity assessment (Lucas et al. 2017). Here, we sequenced 567 cox1 sequences from freshwater benthic oligochaetes in Alberta, which provides a valuable addition to Canadian oligochaete taxonomy. Previous studies have shown that cox1, ITS2 and morphology-based oligochaete phylogenies tend to be congruent, suggesting that our findings, which are based on the cox1 gene alone, should be well supported (Achurra et al. 2011, Vivien et al. 2017). This DNA barcoding effort yielded 157 unique sequence groups that, once analyzed, predicted the presence of 21 unique genera and 37 putative species. A number of the predicted genera/species did not have any sequence matches over $90 \%$ nucleotide identity in GenBank, and for some, the nucleotide identity of the closest match was below $80 \%$ (Table S2). The fact that numerous GenBank entries were identified as $T$. tubifex with some sharing only $87 \%$ nucleotide identity with another T. tubifex highlights a challenge with relying on DNA barcoding and BLAST as the sole method of identifying species. As has been indicated in previous studies, often any small pink worm found in an aquatic environment is considered a 'Tubifex' without further validation. Features used for morphological identification, such as the presence of chaetae, can often become fragile and deteriorate in a sample that has been preserved, thereby limiting accurate identification even when morphological traits are used (Vivien et al. 2017). These difficulties may lead to similar small pink worms falling under the umbrella name ' $T$. tubifex,' which we believe may be reflected in the fact that when we employ unbiased phylogenetic analyses to the cox1 sequences, we find evidence for cryptic speciation in the Tubifex and Limnodrilus genera with 5 and 8 separate predicted species, respectively. All 4 of the OTUs that were found positive for $M$. cerebralis using qPCR were also the most abundant worm species collected. This observation may be related to the low $M$. cerebralis infection prevalence overall, as one might expect that hosts that are rarer would be less likely to be found positive if infection success remained constant. It is important to note that these qPCR-positive results do not guarantee the worms are able to complete the parasite life cycle. While the implications of these unique taxonomic groups of Tubifex for M. cerebralis transmission remain unknown, the role these Tubifex play in the progression of whirling disease in Alberta, particularly Tubifex sp. T3, should be a focus of future studies.

Because $M$. cerebralis was first detected in southern Alberta and impacts of whirling disease were first observed in the Oldman River drainage basin (Veillard \& James 2020), we were curious if the geographical range of $M$. cerebralis in Alberta was being dictated by variation in the worm host population or was simply related to parasite invasion delay. Worm species across watersheds were consistent in both abundance and proportion, with most areas having approximately $50 \%$ Tubifex sp. complex worms. The presence and abundance of specific Tubifex and Limnodrilus taxonomic groups displayed variation between watersheds (Fig. 2). However, it is unclear whether these differences are due to sample size, timing of sampling efforts or true variation in the populations. Oligochaete distribution between sites is likely more affected by local water conditions than any large-scale differences across our study area (Zendt \& Bergersen 2000). This suggests that susceptible worm hosts likely occupy habitats across the province.

Molecular methods, including qPCR, have been shown to be sensitive and specific tools for surveillance of invasive species (Brown et al. 2016) and parasites (Lass et al. 2009, Rudko et al. 2018) within water bodies (Egan et al. 2015). In this study, we aimed to demonstrate the utility of such an approach when incorporating environmental life cycle stages for detecting invasive parasites in water bodies. Molecular assays can answer basic questions about parasite distribution and help determine compatible intermediate and definitive hosts in the invaded habitat, which is especially important when managing an invasive species (Klymus et al. 2020). While our study confirms that fish sampling should remain the gold-standard for whirling disease surveillance 
efforts due to its higher sensitivity, environmental monitoring or inclusion of surveillance of the Tubifex host could be valuable to implement when fish sampling is limited, or when sampling time does not correspond to the presence of sufficient numbers of juvenile fish. To increase the sensitivity for detecting $M$. cerebralis in the Tubifex host, we recommend that future sampling efforts follow standardized oligochaete collection methods targeting 300 individual worms per location (Alexander et al. 2011, Veillard \& James 2020). Moreover, to achieve control of $M$. cerebralis, the life cycle must be broken, leading to a local die off, which is most feasible at a small scale (Nehring et al. 2018). This type of control measure could be assessed using qPCR testing focused on the environmental and Tubifex lifecycle stages. Nehring et al. (2015) found that the myxospore stage of the parasite can only survive in the environment and be infective to worms for 6 mo to $1 \mathrm{yr}$. Thus, even a seasonal interruption in the life cycle may be sufficient to prevent transmission in the following year. However, $T$. tubifex can survive for a number of years (Timm 2020), suggesting that infected worms may be able to serve as a reservoir for $M$. cerebralis even if the parasite was eliminated from the fish population or environment. Implementation of recovery efforts should build on the confidence that the parasite was significantly reduced or absent from the environment and Tubifex populations, which could be confirmed by the type of testing undertaken in this study. Finally, the release of TAMs from infected worms is seasonal and likely temperature-dependent (Gilbert \& Granath 2001, Allen \& Bergersen 2002, Downing et al. 2002, Pierce et al. 2009). While not directly assessed in this study, the qPCR test developed here could be implemented for water sample analysis. which has been successfully used to determine infection risk based on parasite prevalence in other myxozoan parasites (Hallett \& Bartholomew 2006). Information related to peak TAM abundance in the water could predict peak transmission dates thereby highlighting those fish species that may be most at risk of infection. The high sensitivity of qPCR-based testing makes it ideal for such a monitoring effort, where individual M. cerebralis TAMs are thought to be sufficient to initiate declines in wild self-renewing rainbow trout populations (Nehring \& Thompson 2003).

The new molecular test developed as part of this study has allowed for tracking of the progress of $M$. cerebralis in near real time as it moves through the province of Alberta. This test was designed for amplifying $M$. cerebralis specifically from environmental matrices that are likely to contain other myx- ozoan species. Our intention is that the new monitoring possibilities opened by this test, along with the advancements in Albertan oligochaete phylogenetics, will assist Alberta whirling disease management efforts and provide useful tools for areas newly invaded by this parasite.

Acknowledgements. We acknowledge assistance from Alberta Environment and Parks technicians and staff, who were instrumental in sample collection and project coordination. Funding for the project was provided by Alberta Environment and Parks (to P.C.H.).

\section{LITERATURE CITED}

Achurra A, Elejalde MA, Rodriguez P (2011) Phylogenetic analysis of oligochaete Tubificinae (Annelida:Clitellata) based on mitochondrial sequence data. Invertebr Syst 25:208-218

Alexander JD, Kerans BL, Koel TM, Rassumssen C (2011) Context specific parasitism in Tubifex tubifex in geothermally influenced stream reaches in Yellowstone National Park. J N Am Benthol Soc 30:853-867

Allen MB, Bergersen EP (2002) Factors influencing the distribution of Myxobolus cerebralis, the causative agent of whirling disease, in the Cache la Poudre River, Colorado. Dis Aquat Org 49:51-60

American Fisheries Society-Fish Health Section (2006) AFS-FHS Blue Book: suggested procedures for detection and identification of certain finfish and shellfish pathogens. American Fisheries Society, Bethesda, MD

Ardura A, Zaiko A, Borrell YJ, Samuiloviene A, GarciaVazquez E (2017) Novel tools for early detection of a global aquatic invasive, the zebra mussel Dreissena polymorpha. Aquat Conserv 27:165-176

Arsan EL, Hallett SL, Bartholomew JL (2007) Tubifex tubifex from Alaska and their susceptibility to Myxobolus cerebralis. J Parasitol 93:1332-1342

* Bartholomew JL, Kerans BL, Hedrick RP, Macdiarmid SC, Winton JR (2005) A risk assessment based approach for the management of whirling disease. Rev Fish Sci 13: 205-230

Baxa DV, Kelley GO, Mukkatira KS, Beauchamp KA, Rasmussen C, Hedrick RP (2008) Arrested development of the myxozoan parasite, Myxobolus cerebralis, in certain populations of mitochondrial 16S lineage III Tubifex tubifex. Parasitol Res 102:219-228

*Beauchamp KA, Kathman RD, McDowell TS, Hedrick RP (2001) Molecular phylogeny of tubificid oligochaetes with special emphasis on Tubifex tubifex (Tubificidae). Mol Phylogenet Evol 19:216-224

Beauchamp KA, Gay M, Kelley GO, El-Matbouli M, Kathman RD, Nehring RB, Hedrick RP (2002) Prevalence and susceptibility of infection to Myxobolus cerebralis, and genetic differences among populations of Tubifex tubifex. Dis Aquat Org 51:113-121

Bely AE, Wray GA (2004) Molecular phylogeny of naidid worms (Annelida: Clitellata) based on cytochrome oxidase I. Mol Phylogenet Evol 30:50-63

Brinkhurst RO (1978) Freshwater Oligochaeta in Canada. Can J Zool 56:2166-2175 
Brown EA, Chain FJJ, Zhan A, MacIsaac HJ, Cristescu ME (2016) Early detection of aquatic invaders using metabarcoding reveals a high number of non-indigenous species in Canadian ports. Divers Distrib 22:1045-1059

Canadian Food Inspection Agency (2016) First case of whirling disease in Canada. https://www.canada.ca/ en/food-inspection-agency/news/2016/08/first-case-ofwhirling-disease-in-canada.html (accessed 21 November 2019)

Cavender WP, Wood JS, Powell MS, Overturf K, Cain KD (2004) Real-time quantitative polymerase chain reaction (QPCR) to identify Myxobolus cerebralis in rainbow trout Oncorhynchus mykiss. Dis Aquat Org 60:205-213

Chiaramonte LV, Burbank D, Scott R, Trushenski JT (2018) Comparison of sampling and detection methods for chinook salmon and steelhead naturally infected with Myxobolus cerebralis. J Aquat Anim Health 30:57-64

Dash MC (1970) A taxonomic study of Enchytraeidae (Oligochaeta) from Rocky Mountain forest soils of the Kananaskis region of Alberta, Canada. Can J Zool 48: 1429-1435

* Downing DC, McMahon TE, Kerans BL, Vincent ER (2002) Relation of spawning and rearing life history of rainbow trout and susceptibility to Myxobolus cerebralis infection in the Madison River, Montana. J Aquat Anim Health 14: 191-203

Egan SP, Grey E, Olds B, Feder JL, Ruggiero ST, Tanner CE, Lodge DM (2015) Rapid molecular detection of invasive species in ballast and harbor water by integrating environmental DNA and light transmission spectroscopy. Environ Sci Technol 49:4113-4121

Folmer O, Black M, Hoeh W, Lutz R, Vrijenhoek R (1994) DNA primers for amplification of mitochondrial cytochrome c oxidase subunit I from diverse metazoan invertebrates. Mol Mar Biol Biotechnol 3:294-299

Fontes I, Hartikainen H, Holland JW, Secombes CJ, Okamura B (2017) Tetracapsuloides bryosalmonae abundance in river water. Dis Aquat Org 124:145-157

Gilbert MA, Granath WO (2001) Persistent infection of Myxobolus cerebralis, the causative agent of salmonid whirling disease, in Tubifex tubifex. J Parasitol 87: 101-107

Gilbert MA, Granath WO (2003) Whirling disease of salmonid fish: life cycle, biology, and disease. J Parasitol 89: 658-667

Gillespie DC, Evelyn TPT, Frantsi C, MacKelvie RM, Neufeld N (1974) Methods for the detection of certain pathogens of salmonid fishes. Misc Spec Publ 23. Department of the Environment, Fisheries and Marine Service, Ottawa

* Government of Canada (2002) Consolidated federal laws of Canada. Species at Risk Act. https://laws.justice.gc.ca/ eng/acts/S-15.3/page-17.html\#h-435647 (accessed 21 November 2019)

* Guindon S, Dufayard JF, Lefort V, Anisimova M, Hordijk W, Gascuel O (2010) New algorithms and methods to estimate maximum-likelihood phylogenies: assessing the performance of PhyML 3.0. Syst Biol 59:307-321

Hallett SL, Bartholomew JL (2006) Application of a real-time PCR assay to detect and quantify the myxozoan parasite Ceratomyxa shasta in river water samples. Dis Aquat Org 71:109-118

Hallett SL, Lorz HV, Atkinson SD, Rasmussen C, Xue L, Bartholomew JL (2009) Propagation of the myxozoan parasite Myxobolus cerebralis by different geographic and genetic populations of Tubifex tubifex: an Oregon perspective. J Invertebr Pathol 102:57-68

*Hallett SL, Ray RA, Hurst CN, Holt RA, Buckles GR, Atkinson SD, Bartholomew JL (2012) Density of the waterborne parasite Ceratomyxa shasta and its biological effects on salmon. Appl Environ Microbiol 78:3724-3731

* Haque MIM, Rubayet Ul Alam ASM, Akter N, Siddique MA, Sultana M, Hossain MA, Hasan M (2020) Molecular characterization of 'tubifex worms' based on 16S rRNA and cytochrome c oxidase subunit I. Aquacult Rep 16: 100292

Hoffman GL, Dunbar CE, Bradford A (1962) Whirling disease of trouts caused by Myxosoma cerebralis in the United States. Spec Sci Rep 427. US Department of the Interior, Fish and Wildlife Service, Washington, DC

*Hogge C, Campbell M, Johnson K (2004) Discriminating between a neurotropic Myxobolus sp. and M. cerebralis, the causative agent of salmonid whirling disease. J Aquat Anim Health 16:137-144

* Huelsenbeck JP, Ronquist F (2001) MRBAYES: Bayesian inference of phylogenetic trees. Bioinformatics 17: $754-755$

Kelley GO, Zagmutt-Vergara FJ, Leutenegger CM, Myklebust KA and others (2004) Evaluation of five diagnostic methods for the detection and quantification of Myxobolus cerebralis. J Vet Diagn Invest 16:202-211

Klymus KE, Merkes CM, Allison MJ, Goldberg CS and others (2020) Reporting the limits of detection and quantification for environmental DNA assays. Environ DNA 2: 271-282

Lass A, Pietkiewicz H, Modzelewska E, Dumètre A, Szostakowska B, Myjak P (2009) Detection of Toxoplasma gondii oocysts in environmental soil samples using molecular methods. Eur J Clin Microbiol Infect Dis 28: 599-605

Kiu Y, Fend SV, Martinsson S, Erséus C (2017) Extensive cryptic diversity in the cosmopolitan sludge worm Limnodrilus hoffmeisteri (Clitellata, Naididae). Org Divers Evol 17:477-495

Kucas BT, Quinteros C, Burnett-Seidel C, Elphick JR (2017) An evaluation of molybdenum toxicity to the oligochaete, Tubifex tubifex, and early-life stages of brown trout, Salmo trutta. Bull Environ Contam Toxicol 98:747-752

* Markiw ME, Wolf K (1974) Myxosoma cerebralis: isolation and concentration from fish skeletal elements - sequential enzymatic digestions and purification by differential centrifugation. J Fish Res Board Can 31:15-20

* Markiw ME, Wolf K (1983) Myxosoma cerebralis (Myxozoa: Myxosporea) etiologic agent of salmonid whirling disease requires tubificid worm (Annelida: Oligochaeta) in its life cycle. J Protozool 30:561-564

McGinnis S, Kerans BL (2013) Land use and host community characteristics as predictors of disease risk. Landsc Ecol 28:29-44

Mumy KL, Findlay RH (2004) Convenient determination of DNA extraction efficiency using an external DNA recovery standard and quantitative-competitive PCR. J Microbiol Methods 57:259-268

Nehring RB, Thompson KG (2003) Whirling disease investigations. Federal Aid Project F-237-R10. Job Progress Report. Colorado Division of Wildlife, Fort Collins, CO

Nehring RB, Walker PG (1996) Whirling disease in the wild: a fresh approach to stock assessment. Fisheries 21:28-30

Nehring R, Thompson KG, Taurman KA, Shuler DL (2002) Laboratory studies indicating that living brown trout 
Salmo trutta expel viable Myxobolus cerebralis myxospores. Am Fish Soc Symp 29:125-134

Nehring RB, Schisler G, Chiaramonte L, Horton A, Poole B (2015) Assessment of the long-term viability of the myxospores of Myxobolus cerebralis as determined by production of the actinospores by Tubifex tubifex. J Aquat Anim Health 27:50-56

Nehring RB, Alves J, Nehring JB, Felt B (2018) Elimination of Myxobolus cerebralis in Placer Creek, a native cutthroat trout stream in Colorado. J Aquat Anim Health 30: 264-279

Nurminen M (1973) Enchytraeidae (Oligochaeta) from the vicinity of Montreal, Canada. Ann Zool Fenn 10: 399-402

Pierce R, Podner C, Davidson M, Vincent ER (2009) Correlation of fluvial rainbow trout spawning life history with severity of infection by Myxobolus cerebralis in the Blackfoot River Basin, Montana. Trans Am Fish Soc 138: 251-263

Puillandre N, Lambert A, Brouillet S, Achaz G (2012) ABGD, Automatic Barcode Gap Discovery for primary species delimitation. Mol Ecol 21:1864-1877

Rasmussen C, Zickovich J, Winton JR, Kerans BL (2008) Variability in triactinomyxon production from Tubifex tubifex populations from the same mitochondrial DNA lineage infected with Myxobolus cerebralis, the causative agent of whirling disease in salmonids. J Parasitol 94:700-708

Rasmussen JB, Taylor EB (2009) Status of the Athabasca rainbow trout Oncorhynchus mykiss in Alberta. Alberta Wildlife Status Report no. 66, Government of Alberta-Fish and Wildlife Division. https://open.alberta. $\mathrm{ca} /$ publications/9780778570776\#summary

Richey CA, Kenelty KV, Van Stone Hopkins K, Stevens BN and others (2018) Distribution and prevalence of $M y x-$ obolus cerebralis in postfire areas of Plumas National Forest: utility of environmental DNA sampling. J Aquat Anim Health 30:130-143

Rognlie MC, Knapp SE (1998) Myxobolus cerebralis in Tubifex tubifex from a whirling disease epizootic in Montana. J Parasitol 84:711-713

Ronquist F, Huelsenbeck JP (2003) MrBayes 3: Bayesian phylogenetic inference under mixed models. Bioinformatics 19:1572-1574

Rudko SP, Reimink RL, Froelich K, Gordy MA, Blankespoor CL, Hanington PC (2018) Use of qPCR-based cercario-

Editorial responsibility: Catherine Collins, Jouy-en-Josas, France

Reviewed by: H. Hartikainen and 2 anonymous referees metry to assess swimmer's itch in recreational lakes. EcoHealth 15:827-839

Skirpstunas RT, Hergert JM, Baldwin TJ (2006) Detection of early stages of Myxobolus cerebralis in fin clips from rainbow trout (Onchorynchus [sic] mykiss). J Vet Diagn Invest 18:274-277

* Sturmbauer C, Opadiya GB, Niederstatter H, Riedmann A, Dallinger R (1999) Mitochondrial DNA reveals cryptic oligochaete species differing in cadmium resistance. Mol Biol Evol 16:967-974

Timm T (2020) Observations on the life cycle of aquatic Oligochaeta in aquaria. Zoosymposia 17:102-120

* Trebitz AS, Hoffman JC, Darling JA, Pilgrim EM and others (2017) Early detection monitoring for aquatic nonindigenous species: optimizing surveillance, incorporating advanced technologies, and identifying research needs. J Environ Manag 202:299-310

US EPA (United States Environmental Protection Agency) (2012) Method 1611: enterococci in water by TaqMan® quantitative polymerase chain reaction (qPCR) assay. EPA-821-R-12-008. www.epa.gov/sites/production/files/ 2015-08/documents/method_1611_2012.pdf

Veillard M, James C (2020) Status of whirling disease in the Crowsnest River 2019. Tech Rep. Government of Alberta, Ministry of Environment and Parks, Edmonton

Vincent ER (1996) Whirling disease and wild trout: the Montana experience. Fisheries 21:32-33

*Vivien R, Holzmann M, Werner I, Pawlowski J, Lafont M, Ferrari BJD (2017) Cytochrome c oxidase barcodes for aquatic oligochaete identification: development of a Swiss reference database. PeerJ 5:e4122

Wilrich C, Wilrich PT (2009) Estimation of the POD Function and the LOD of a qualitative microbiological measurement method. J AOAC Int 92:1763-1772

K Zendt JS, Bergersen EP (2000) Distribution and abundance of the aquatic oligochaete host Tubifex tubifex for the salmonid whirling disease parasite Myxobolus cerebralis in the Upper Colorado River Basin. N Am J Fish Manag 20:502-512

Zielinski CM, Lorz HV, Bartholomew JL (2010) Detection of Myxobolus cerebralis in the Lower Deschutes River Basin, Oregon. N Am J Fish Manag 30:1032-1040

* Zielinski CM, Lorz HV, Hallett SL, Xue L, Bartholomew JL (2011) Comparative susceptibility of Deschutes River, Oregon, Tubifex tubifex populations to Myxobolus cerebralis. J Aquat Anim Health 23:1-8

Submitted: July 21, 2020

Accepted: April 27, 2021

Proofs received from author(s): June 24, 2021 